\title{
Bait increases the precision in count data from remote underwater video for most subtidal reef fish in the warm-temperate Agulhas bioregion
}

\author{
A. T. F. Bernard ${ }^{1,2, *}$, A. Götz ${ }^{2}$ \\ ${ }^{1}$ Zoology and Entomology Department, Rhodes University, Grahamstown 6139, South Africa \\ ${ }^{2}$ Elwandle Node, South African Environmental Observation Network, Grahamstown 6139, South Africa
}

\begin{abstract}
Baited remote underwater video (BRUV) has been identified in the literature as a powerful long-term monitoring tool for subtidal rocky reef fish communities. To test this, a repeated-measures field experiment comparing unbaited remote underwater video (RUV) with BRUV was conducted in the Tsitsikamma National Park Marine Protected Area between June 2008 and February 2010. The results demonstrate that BRUV was more efficient at surveying the entire fish community, specifically invertebrate carnivores, generalist carnivores and cartilaginous species. On the other hand, RUV was more effective at surveying microinvertebrate carnivores. High variability in the RUV data resulted in the method requiring a greater number of samples to achieve the same diagnostic power as BRUV. However, RUV required a shorter deployment and post-sampling video analysis time, making it more time efficient. Baited remote underwater video was more sensitive in the detection of differences in abundance between habitat types, while the RUV data were more prone to an intra-species methodological bias linked to the percentage of reef visible in the frame of view. The scale of the response to the presence of bait was inconsistent among species, indicating that behaviour determined the area surveyed within the bait plume of BRUV. The benefits gained by sampling the fish community with RUV do not outweigh those obtained by altering the community through the presence of bait. However, in combination, the 2 methods are highly effective at monitoring the subtidal fish communities in the Agulhas bioregion of South Africa.
\end{abstract}

KEY WORDS: BRUV - Baited remote underwater video - RUV - Remote underwater video · Method comparison - Temperate - Rocky reef - MPA - Marine protected area - Monitoring · South Africa

\section{INTRODUCTION}

Baited remote underwater video (BRUV) was originally tested as an alternative non-destructive sampling method to bottom long-line (Ellis \& DeMartini 1995) and demersal trawls (Priede \& Merrett 1996). Over the last decade, the BRUV method has gained considerable support with research investigating the effects of fishing and protection on ecosystems and species (Babcock et al. 1999, Willis et al. 2003, Cappo et al. 2007a, Malcolm et al. 2007, Watson et al. 2007,
2009, Goetze et al. 2011, Langlois et al. 2011, 2012, McLean et al. 2011) and the effect of environmental conditions on fish distribution patterns (Brooks et al. 2011, Langlois et al. 2011, Moore et al. 2011, Birt et al. 2012, Cheung et al. 2012). At the same time, the BRUV method has undergone further development (Willis \& Babcock 2000, Harvey et al. 2002, 2007 , Watson et al. 2005, 2010, Stobart et al. 2007, Langlois et al. 2010, Merritt et al. 2011) and rigorous testing against traditional fish monitoring methods, such as angling, underwater visual census (UCV), traps and 
trawls (Willis et al. 2000, Cappo et al. 2004, Watson et al. 2005, Colton \& Swearer 2010, Pelletier et al. 2011, Harvey et al. 2012). The core strengths lie in the method's ability to survey components of the fish community typically missed by UVC techniques, such as large piscivorous fish (Willis et al. 2000, Cappo et al. 2004, Brooks et al. 2011), the higher diagnostic power achieved through reduced variability in the data (Watson et al. 2005, Harvey et al. 2007, Stobart et al. 2007, Langlois et al. 2010) and the ability to provide accurate measures of fish length when set up with stereo-cameras (Harvey \& Shortis 1996, Harvey et al. 2004, Watson et al. 2009). Data collected with BRUV are not biased by the presence of an observer in the water that can alter the behaviour of the fish, and observer bias during analysis is kept to a minimum, as the video is available for reanalysis if erroneous data are detected (Cappo et al. 2003, $2007 b$ ). Furthermore, BRUV is a non-destructive and non-extractive sampling tool and is thus ideally suited to monitor protected fish populations inside marine reserves (Willis et al. 2000, Cappo et al. 2007b).

As with all survey methods, BRUV is characterised by a number of shortcomings. For example, past studies indicate that BRUV is unable to survey herbivorous fish as efficiently as UVC (Colton \& Swearer 2010), or small cryptic fish as efficiently as diveroperated video (Watson et al. 2005). The postsampling analysis of the video footage is timeconsuming and a bottleneck in the data processing (Cappo et al. 2003, Colton \& Swearer 2010). Standardisation of count data from BRUV samples is problematic, as the sampled area is difficult to quantify (Cappo et al. 2003, 2007a) due to interacting uncertainties around the size of the bait plume in shallow coastal environments (Cappo et al. 2004, Stobart et al. 2007), variable species-specific responses (Bailey \& Priede 2002, Colton \& Swearer 2010), and the influence of water clarity (Cappo et al. 2004). As a result, most studies only provide a relative abundance measure. The apparent inadequacies in the BRUV's ability to survey the entire fish community is an area of concern, and it has been suggested that a combination of methods is required if a study aims to assess the biodiversity of a fish assemblage (Watson et al. 2005, Colton \& Swearer 2010).

The RUV method provides a discrete picture of the distribution of fish within the camera's frame of view, free from biases arising from altered fish behaviour in the presence of bait, or difficulties evaluating the sampled area. It is therefore an appealing monitoring option, as it is one of the closest examples of an unbiased survey method. Very few RUV surveys of fish communities have been conducted, and most examples involve experimental method comparisons (Francour et al. 1999, Watson et al. 2005, Harvey et al. 2007, Pelletier et al. 2012). Data collected with RUV are subject to high spatial and temporal variability as changes in abundance, resulting from oceanographic or habitat variability, are not dampened by the attraction effect of the bait (Watson et al. 2005). As a result, RUV requires a considerably higher sampling effort to produce data with comparable statistical power to BRUV (Watson et al. 2005, Harvey et al. 2007). However, RUV and UVC produce comparable data for the dominant and conspicuous components of the fish community (Francour et al. 1999).

To date, limited research has been conducted in South Africa with either the BRUV or RUV method. Although numerous international methodological studies have investigated the pros and cons of BRUV, and to a lesser degree RUV, many questions still remain regarding the optimal application of the methods, their ability to effectively survey different components of the fish community, and the extent of the associated bias. The aim of this study was to determine the optimal sampling time and, by conducting a comparative field experiment, to assess the feasibility of applying remote underwater video techniques to survey the subtidal reef fish communities in the Agulhas bioregion of South Africa.

\section{MATERIALS AND METHODS}

\section{Study area}

The research was conducted in the Tsitsikamma National Park (TNP) Marine Protected Area (MPA) situated in the centre of the warm-temperate Agulhas bioregion, which stretches along the southern coastline of South Africa (Fig. 1A). The TNP MPA is the oldest (proclaimed in 1964), and one of the largest $\left(323 \mathrm{~km}^{2}\right)$, no-take MPAs in Africa. The Rheeders Reef complex lies to the east of the Storms River mouth in the centre of the MPA (Fig. 1B). It is a diverse reef complex consisting of large expanses of solid high and low profile rocky reef, together with intermittent sand patches (Fig. 1C). The subtidal communities provide one of the best examples of pre-exploitation nearshore ecosystems available in southern Africa, allowing for a more thorough assessment of the ability of remote camera methods to survey subtidal rocky reef fish communities in the Agulhas bioregion. 


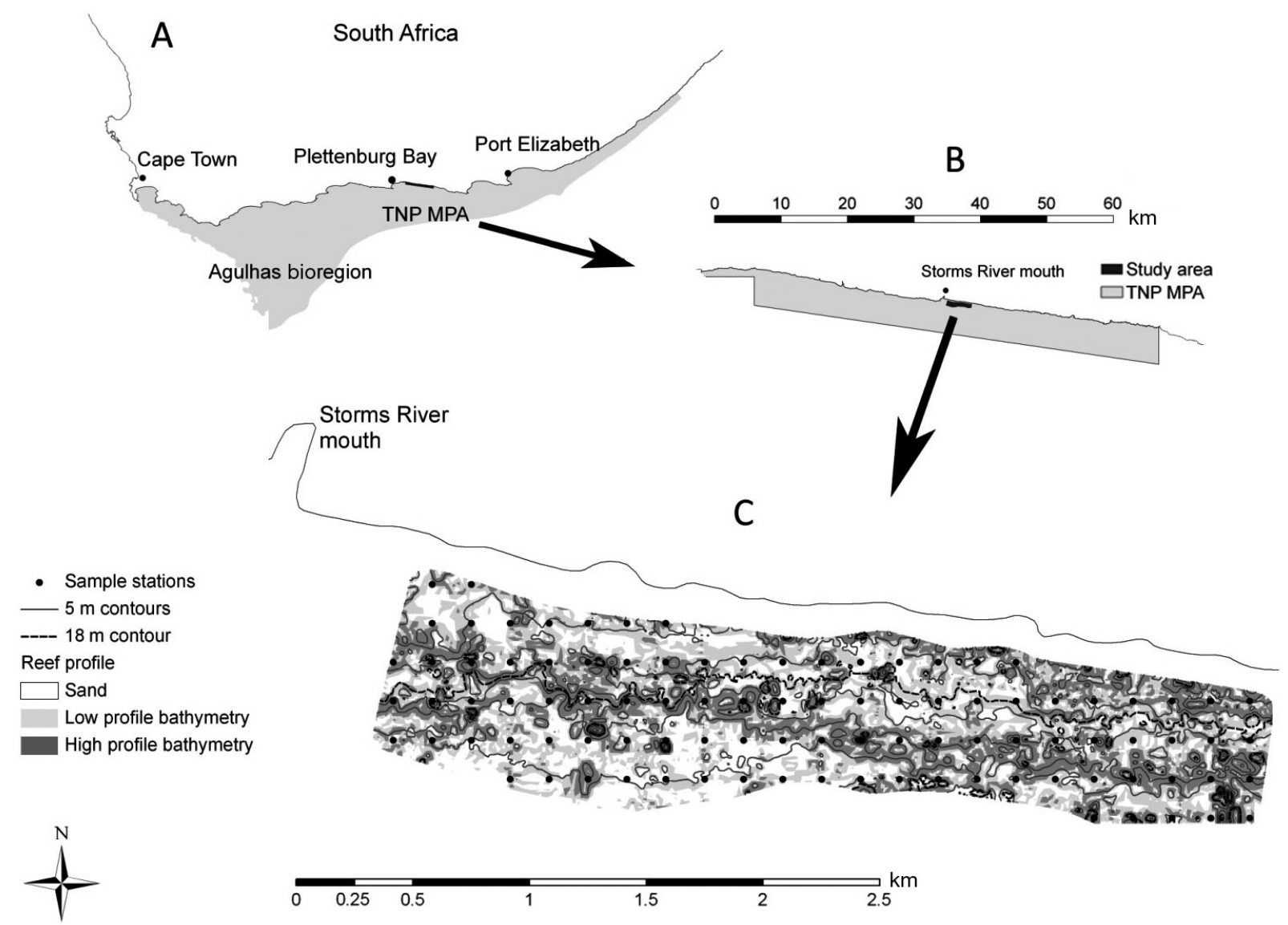

Fig. 1. (A) The location of the Tsitsikamma National Park Marine Protected Area (TNP MPA) in South Africa, with (B) the position of the Rheeders Reef complex within the TNP MPA, and (C) the detailed bathymetry of the Rheeders Reef complex

\section{Site stratification}

The study area was stratified according to depth and reef profile. Stratification according to the permanent features of an environment allows collection of representative samples when the study area is not homogenous, and improves the overall precision of the sampling effort (Murray et al. 2001). For this, a detailed bathymetric map was developed from data collected by Bennett (2007) and during this study, with a high resolution GPS linked echo-sounder. The latitude, longitude and depth data were interpolated to create a 3-dimensional bathymetric contour map in GIS (ArcMap, version 9.2) (Fig. 1C).

A $150 \times 150 \mathrm{~m}$ grid was overlaid onto the bathymetric map, and each grid-cell was classed according to the stratification criteria beneath it (Bennett et al. 2009): depth was classed as shallow (5-18 m) or deep $(18-30 \mathrm{~m})$, and profile was classed as low or high profile bathymetry. If a grid-cell was dominated by sand, it was dropped as a possible sampling station. During each sampling trip, the grid-cells from within each class were randomly selected, with even sample allocation between classes. To avoid recounting the same individuals, adjacent grid-cells were excluded from selection, and sampling stations were separated by at least $300 \mathrm{~m}$. The sampling procedure was further randomised by targeting classes in a random sequence. The approach above follows the protocol described by Götz (2005) and Bennett (2007).

A repeated measures experimental design was employed, whereby both RUV and BRUV samples were collected at each sampling station. At all 28 stations, the RUV sample was collected prior to the BRUV sample so as not to bias the RUV data by attracting fish into the area with the bait, and a 10 min break between deployments at a station was selected to allow the fish community to settle. Each deployment was $60 \mathrm{~min}$ in duration. The effect of seasonal variation in oceanographic conditions and fish behaviour was taken into account by conducting the study over 4 sequential summer and winter seasons between June 2008 and February 2010. 


\section{Remote underwater video system}

The video system consisted of a custom made, weighted $(20 \mathrm{~kg})$, stainless steel tripod, fitted with a standard definition remote video camera positioned horizontally $\sim 1 \mathrm{~m}$ off the bottom (Fig. 2). The camera lens had a focal length of $24 \mathrm{~mm}$, equivalent to a $73.7^{\circ}$ horizontal angle of view. The camera provided live feed to the surface, and the stations were recorded on a digital video recorder with a display screen allowing for real time viewing and ensuring that the tripod was correctly deployed before starting to record. The boat was on anchor for the duration of sampling at each station. For the baited samples, the tripod was fitted with a $1 \mathrm{~m}$ bait-arm holding a perforated PVC container designed to contain $1 \mathrm{~kg}$ of crushed pilchard Sardinops sagax in the field of view of the camera.

\section{Video analysis}

The videos were analysed with Adobe Premiere (version CS4) that allowed for frame by frame playback and picture adjustment for murky conditions. The relative abundance was calculated for each species observed, and was defined as the maximum number of individuals $(\operatorname{Max} N)$ in the field of view at one time (Cappo et al. 2003, Priede et al. 1994). For consistency, only 1 observer analysed the video footage.

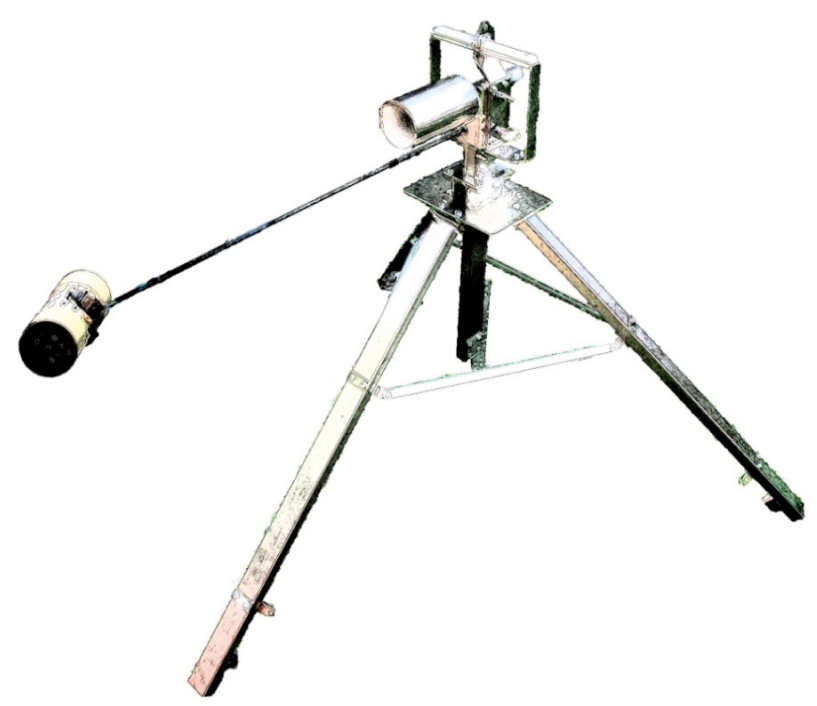

Fig. 2. The tripod deployed during the survey. The bait-arm holding the PVC bait container is attached. The cable and rope, which were attached to the top of the tripod, are not shown

\section{Environmental factors}

Water clarity at each station was determined by calculating the relative change in size of individual roman seabream, Chrysoblephus laticeps, from the bait container ( $1 \mathrm{~m}$ from the camera) to the point where their identifying features were no longer visible. Height and fork length of individuals were measured once, when they were actively feeding perpendicular to the bait container $\left(L_{\mathrm{bc}}\right)$, and then again, when the same individual was swimming at the limit of visibility $\left(L_{\mathrm{ve}}\right)$. All measurements were made with the measurement tool in ArcMap (version 9.3). Visibility (Vis) was estimated as:

$$
\operatorname{Vis}(\mathrm{m})=\frac{L_{\mathrm{bc}}}{L_{\mathrm{ve}}}+1 \mathrm{~m}
$$

To account for the position of the bait container, $1 \mathrm{~m}$ was added to the visibility estimate. Roman seabream (roman) were selected because of their abundance within the survey area, striking colour patterns and aggressive behaviour around the bait container. This increased the likelihood of seeing an individual feeding on the bait and at the visibility limit. Where roman weren't recorded at a station (3 stations), the average visibility observed on the day was used. Secchi depth and water turbidity are alternative measures; however, both methods do not always reflect the actual water clarity over the reef, due to strong thermoclines separating water layers with different characteristics (Götz 2005).

With the visibility estimate it was then possible to calculate the horizontal area $\left(H_{a}\right)$ visible in each video. To do this, the radians in view (calculated by dividing the horizontal angle of view, $H_{\theta}$, of the video camera by $360^{\circ}$ ) was multiplied by the area of visibility, $\pi(\operatorname{Vis})^{2}$ :

$$
H_{\mathrm{a}}\left(\mathrm{m}^{2}\right)=\frac{H_{\theta}}{360} \times \pi(\text { Vis })^{2}
$$

It is acknowledged that the bait plume would have attracted and concentrated certain species from further downstream of the bait container. As a result, the data were kept in count form for the RUV and BRUV comparison, while area was used as an offset in the regression analysis to account for variability in water visibility between stations. The area of reef in view (factor: visible reef) was calculated by analysing the percentage cover of reef in the video frame using Vidana (Version 1.0.1be) (Hedley 2003). Water temperature was recorded for each sample with a temperature logger attached to the tripod. Depth was 
measured with the boat's echo sounder, and reef profile was inferred from the bathymetric map (Fig. 1C) and confirmed from the video footage.

\section{Optimal deployment time}

Non-linear mixed effects (NLME) models were applied to analyse and compare the optimal deployment time for the remote video methods because they accommodate repeated measures data (Lindstrom \& Bates 1990). To be able to accurately predict the optimal deployment time of the remote video methods, the NLME model was fitted with a 2 parameter logistic-ogive function (Weyl \& Booth 1999) to determine average accumulation levels of species, and was defined as:

$$
P=\frac{1}{1+\exp \left(\frac{T-T_{50}}{\delta}\right)}
$$

and

$$
P=\frac{1}{1+\exp \left(-\ln 19 \frac{\left(T-T_{50}\right)}{T_{95}-T_{50}}\right)}
$$

where $P$ is the probability that species accumulation is $50 \%$ saturated at time $T\left(T_{50}\right), T_{95}$ is the time at $95 \%$ species accumulation, and $\delta$ is the inverse rate of saturation. The second logistic model can be generalized to have 2 parameters, the standard $T_{50}$, and $T_{X}$ (the probability of being $X$ saturated), to:

$$
P=\frac{1}{1+\exp \left[-\ln \left(\frac{X}{1-X}\right)\left(\frac{T-T_{50}}{T_{X}-T_{50}}\right)\right]}
$$

For the purpose of this study, optimal deployment time was defined as the point at which $95 \%$ of the species recorded had reached their $\operatorname{Max} N, \ln (19)$ or $\ln (0.95 /[1-0.95])$. The NLME analysis was conducted by employing the NLME package (Pinheiro et al. 2011) in the $\mathrm{R}$ environment (version 2.13.0) (R Development Core Team 2011).

\section{Comparison of methods}

Assessment at the community level

Poisson generalized linear mixed effects models (GLMMs) were applied to estimate the effect of bait on the fish community sampled with remote underwater video as they allow for correlation between observations, and are suited to handling the non-normal, dependent data typical of repeated measures studies (Bolker et al. 2009, Zuur et al. 2009).

Of particular interest was the response by the different trophic guilds of fish to the presence of bait. Observed species were separated by class and then grouped by trophic guild (Mann 2000, Branch et al. 2010). Exploratory analysis (following the protocol of Zuur et al. 2010) revealed insufficient data for the piscivores, which were subsequently grouped with the generalist carnivores. Schooling species (maasbanker Trachurus trachurus, piggy Pomadasys olivaceum, and strepie Sarpa salpa) greatly increased the standard error estimates, which is indicative of a poorly fitted model, and so these species were excluded from the analysis (Harvey et al. 2007, Bolker et al. 2009). A total of 6 trophic guilds were identified (Table 1). To avoid statistical over-fitting (Venables \& Dichmont 2004), only covariates that varied between the RUV and BRUV samples at each station were included in the saturated model. The saturated Poisson GLMM was:

$$
\operatorname{Max} N_{i j} \sim \operatorname{Poisson}\left(\mu_{i j}\right) \Rightarrow E\left(\operatorname{Max} N_{i j}\right) \sim \mu_{i j}
$$

Table 1. Description of the different levels employed to sort the observed species according to their trophic guild

\begin{tabular}{|lll|}
\hline Name & Levels & Description \\
\hline Class & Osteichthyes & Bony fish \\
& Chondrichthyes & Cartilaginous fish \\
& Agnatha & Jawless fish \\
Trophic guild & Herbivore & Diet restricted to plant material \\
& Omnivore & Mixed diet of plant and animal material \\
& Microinvertebrate carnivore & Diet restricted to benthic and pelagic microinvertebrates \\
& Invertebrate carnivore & Diet restricted to benthic and pelagic invertebrates \\
& Generalist carnivore & Diet consisting of fish and invertebrate prey \\
& Piscivore & Diet restricted to fish \\
\hline
\end{tabular}




$$
\begin{aligned}
& \eta_{i}=\operatorname{offset}\left(\log \left(\operatorname{Area}_{i j}\right)\right)+\beta_{1}\left(\operatorname{Method}_{i j}\right)+
\end{aligned}
$$

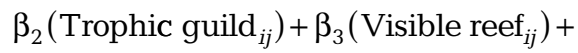

$$
\begin{aligned}
& \beta_{4}\left(\operatorname{Method}_{i j} \text { : Trophic guild } i j\right)+
\end{aligned}
$$

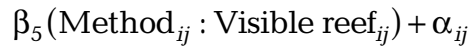

$$
\begin{aligned}
& \alpha_{i j} \sim N\left(0, \sigma_{\alpha}^{2}\right) \\
& \log \left(\mu_{i j}\right)=\eta_{i j}
\end{aligned}
$$

where $E$ is the estimated mean, $\eta$ is the log of the mean (Poisson's mean) and $\beta$ is the regression coefficient.

The first line states that the Max $N$ for species $i$ at station $j$, $\operatorname{Max} N_{i j}$ is Poisson distributed with a mean of $\mu_{i j}$. The second equation is the linear predictor and is typical of a standard generalized linear model (GLM), with an additional offset, $\log \left(\right.$ Area $\left._{i j}\right)$, that accounts for the difference in visible area between stations (Zuur et al. 2009). As the response to the effect of bait was of interest, the interactions between method and station, and method and species within station, was modelled as a random effect $\left(\alpha_{i j}\right)$ with the intercept suppressed. The random intercept is assumed to be normally distributed with a mean of zero and a variance of $\sigma_{\alpha}^{2}$. The GLMMs were fitted by means of the lme4 package (Bates \& Sarkar 2011) in the R environment according to the frameworks provided by Bolker et al. (2009) and Zuur et al. (2009). Model selection was conducted using an Akaike Information Criterion (AIC) based approach, by sequentially removing parameters from the saturated model and selecting the model with the lowest AIC score (Logan 2010). Confidence intervals (CI) around the odds ratios for the effect of bait on $\operatorname{Max} N$ were calculated to facilitate interpretation of the GLMM outputs.

The effect of bait was analysed separately for the dominant species with the GLMM described above, without the random effect of species and with the additional covariate of temperature. The species selected included 2 primary fisheries targets (roman and red steenbras Petrus rupestris), a group of microinvertebrate carnivores (fingerfins, Cheilodactylidae), a potential source of high variability in the community data (steentjie Spondyliosoma emarginatum), a large cartilaginous generalist carnivore (smooth-hound Mustelus mustelus) and a group of small cartilaginous generalist carnivores (catsharks, Scyliorhinidae).

To estimate the ability of the remote video methods to detect spatial variability in the fish populations, Poisson generalized additive models (GAMs) were implemented, as the relationships between the response variable and the continuous predictor variables (i.e. temperature and depth) were non-linear (Zuur et al. 2009). For all the GAMs, discrete covari- ates were included as parametric coefficients, while continuous variables were fitted with tensor product 1-dimensional thin plate splines with 5 basis dimensions. The saturated Poisson GAM for each species was standardised as:

$$
\begin{gathered}
\operatorname{Max}_{i} \sim \operatorname{Poisson}\left(\mu_{i}\right) \Rightarrow E\left(\operatorname{Max}_{i}\right) \sim \mu_{i} \\
\eta_{i}=\alpha+\operatorname{offset}\left(\log \left(\text { Area }_{i}\right)\right)+\text { factor }_{1}\left(\text { Bottom }_{i}\right)+ \\
\text { factor }_{2}\left(\operatorname{Profile}_{i}\right)+f_{1}\left(\text { Temperature }_{i}\right)+ \\
f_{2}\left(\operatorname{Depth}_{i}\right)+f_{3}\left({\text { Visible } \left.\text { reef }_{i}\right)+\varepsilon_{i}}\right. \\
\varepsilon_{i} \sim N\left(0, \sigma^{2}\right) \\
\log \left(\mu_{i}\right)=\eta_{i}
\end{gathered}
$$

where $\alpha$ is the intercept and $\varepsilon$ is the error.

The underlying structure of the Poisson model is similar to that described for the GLMMs, with the offset, $\log \left(\mathrm{Area}_{i}\right)$, differentiating between the visible areas for each of the samples, $i$. The factorial covariates, factor ${ }_{1}\left(\right.$ Bottom $\left._{i}\right)$ and factor ${ }_{2}\left(\right.$ Profile $\left._{i}\right)$, are included as parametric coefficients, while thin plate spline smoothing was applied to the continuous covariates, $f_{1}\left(\right.$ temperature $\left._{i}\right), f_{2}\left(\right.$ depth $\left._{i}\right)$, and $f_{3}\left(\right.$ visible reef $\left._{i}\right)$. The GAM analysis was conducted with the package mgvc (version 1.7-6) (Wood 2011) in the R environment. Model selection followed a likelihood based method of restricted maximum likelihood (REML), whereby the inclusion or exclusion of covariates was derived from likelihood scores. Additionally, null space penalization was employed, whereby covariates were effectively dropped from the model if the smoothing parameters tended towards infinity (Wood 2006).

The statistical power of the data was calculated following the approach of Willis et al. (2003) (See Supplement 1 at www.int-res.com/articles/suppl/m471 p235_supp.pdf for more details). All graphs were created with the Lattice and LatticeExtra packages (Sarkar 2008) in the R environment.

\section{RESULTS}

\section{Environmental characteristics}

Visibility was typical for the region, with a mean \pm $\mathrm{SE}$ of $3.85 \pm 1.46 \mathrm{~m}$, equating to an average horizontal visible area of $9.67 \pm 7.49 \mathrm{~m}^{2}$. The visible reef in the video footage ranged from 0 to $90 \%$, with a mean of $40.54 \pm 21.85 \%$. The water depths surveyed ranged from 10 to $33 \mathrm{~m}$, with an average of $18.96 \pm 5.64 \mathrm{~m}$. Water temperature showed considerable variation $\left(11.4-21.5^{\circ} \mathrm{C}\right)$, with a mean of $17.15 \pm 3.28^{\circ} \mathrm{C}$. 


\section{Optimal deployment time}

The comparison of the rates of species accumulation with increasing deployment time showed that there was no significant difference between the remote video methods at the $50 \%(F=2.17, \mathrm{p}>0.1)$ and $95 \%$ saturation levels $(F=2.74, \mathrm{p}<0.1)$ (Table 2$)$. The RUV method reached the $95 \%$ saturation time (mean $\pm \mathrm{SE})$ at $20.69 \pm 3.14 \mathrm{~min}$, while the BRUV method required $28.64 \pm 4.81 \mathrm{~min}$. Baited remote underwater video recorded higher numbers of species at both the $50 \%(6.62 \pm 0.65$ species $)$ and $95 \%(10.54 \pm 0.70)$ saturation levels when compared to RUV (50\%: $5.90 \pm$ 0.82, $95 \%: 7.49 \pm 0.91$ ) (Fig. 3A). The comparison of the rates of species at $\operatorname{Max} N$ accumulation identified a significant difference in the time taken for RUV $(34.77 \pm 2.90 \mathrm{~min})$ and BRUV $(48.00 \pm 4.15 \mathrm{~min})$ to reach the $95 \%$ saturation level $(F=10.16, \mathrm{p}<0.01)$. Although RUV is predicted to require a significantly shorter deployment time, BRUV records considerably more species within its optimal deployment time $(\mathrm{RUV}=7.84 \pm 0.99 ; \mathrm{BRUV}=11.03 \pm 0.73)$ (Fig. 3B).

\section{Community level analysis}

A total of 48 species of fish were identified to the species level and 5 to the family level. Teleosts dominated the surveys with 36 species correctly identified, while the remainder included 11 species of cartilaginous fish and 1 species of jawless fish (Table 3). The BRUV method recorded $96 \%$ of the observed species (46), while the RUV method recorded only $66 \%$ (32). From the correctly identified species of teleosts, 10 were unique to BRUV and 2 were unique to RUV recordings, while of the 11 cartilaginous species, 6 were unique to BRUV and none were unique to RUV recordings.

Table 2. Optimal deployment times \pm SE for the unbaited (RUV) and baited (BRUV) remote underwater video methods and the corresponding average number of species. The significance levels for the difference in optimal deployment time are provided. Significance levels: ${ }^{-}<0.1_{i}{ }^{*}<0.05_{i}{ }^{* *}<0.01 i^{* * *}<0.001$

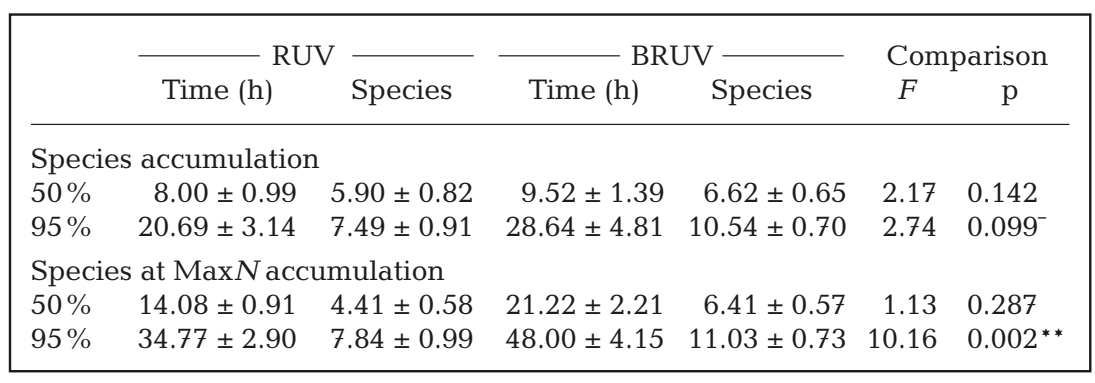

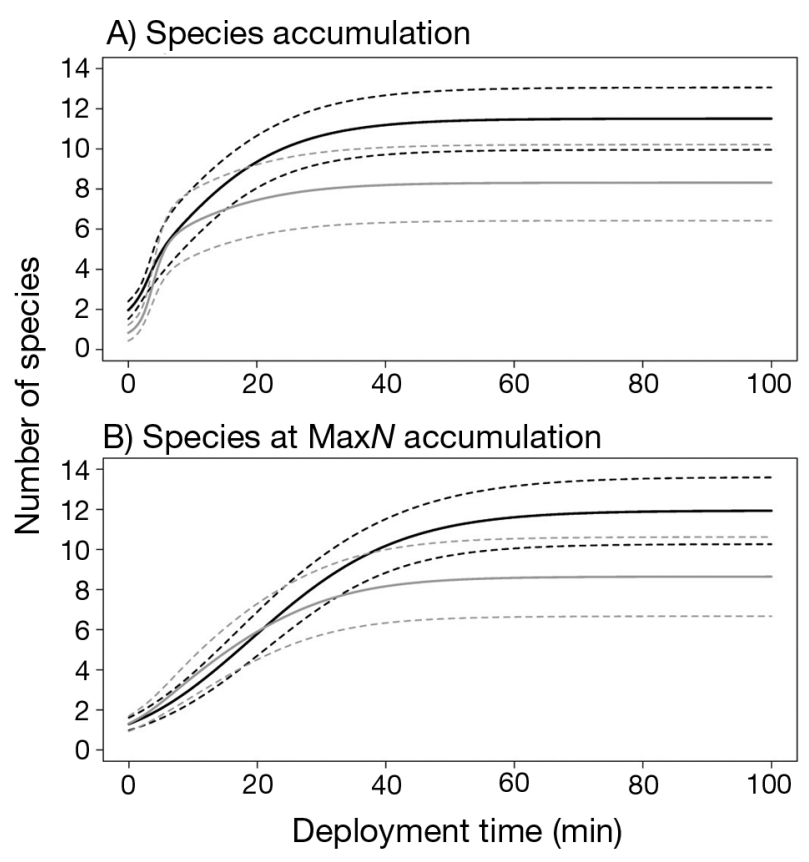

Fig. 3. (A) Predicted accumulation of species and (B) species at $\operatorname{Max} N$ plotted against video duration, extrapolated to $100 \mathrm{~min}$, for the unbaited (gray lines) and baited (black lines) remote underwater video methods. The dashed lines indicate $95 \%$ confidence intervals

\section{The effect of bait on the abundance of trophic guilds}

The saturated model was identified as the best-fit model. The model was slightly over-dispersed $(\phi=$ 1.86); however, this was not excessive (i.e. $\phi<2$ ), indicating that the Poisson model was suitable to analyse the variability in the data (Bolker et al. 2009). The random effects showed a strong positive correlation between BRUV and RUV MaxN data, with $71.6 \%$ of the variability in the BRUV data accounted for by the variability in the RUV data at the station level (Fig. 4A), and $83.7 \%$ of the variability in the data accounted for at the level of species nested in station (Fig. 4B), suggesting that bait accounted for almost all the variability in MaxN between the unbaited and baited samples. A detailed description of the output from the GLMM analysis can be found in Supplement 2 at www.int-res.com/articles/suppl/ m471p235_supp.pdf.

Average $\operatorname{Max} N$ values (mean \pm SE number of individuals) were clearly different between the BRUV and RUV samples for the carti- 


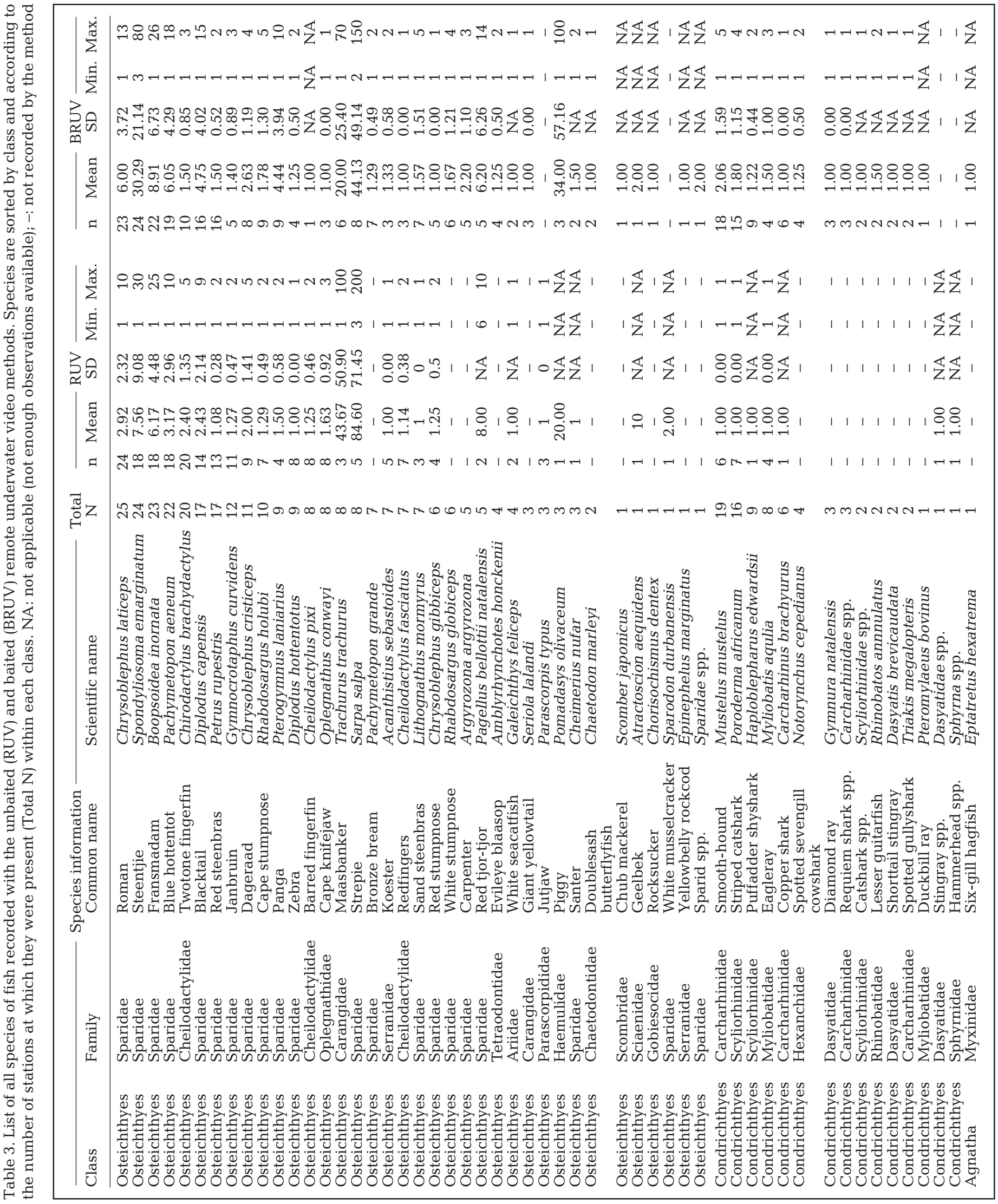




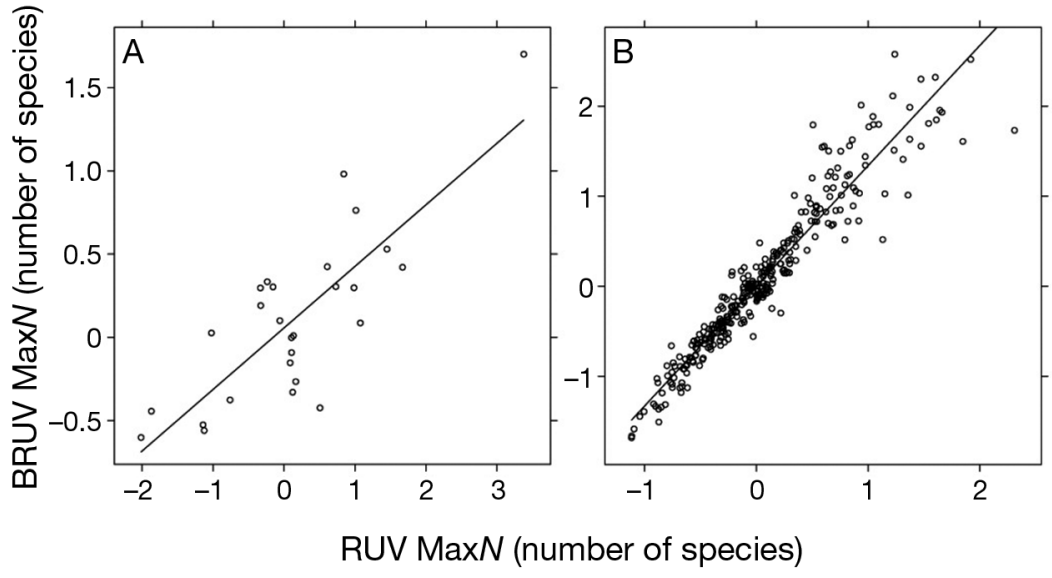

Fig. 4. Correlation of maximum number of individuals $(\operatorname{Max} N)$ between the unbaited (RUV) and baited (BRUV) remote underwater video methods, (A) by station and (B) by species nested in station laginous generalist carnivore group $(\mathrm{BRUV}=1.43 \pm 0.87 ; \mathrm{RUV}=0.24 \pm 0.19)$ (Fig. 5K,L). Similarly, the effect of bait on the bony invertebrate carnivore group was significant, with the average $\operatorname{Max} N$ highly inflated in the BRUV samples $(12.58 \pm 17.06)$, compared to the RUV samples $(2.96 \pm 4.73)$ (Fig. 5E,F). Although there was considerable difference between the $\operatorname{Max} N$ estimates from the BRUV and RUV for the bony generalist carnivore group (BRUV = $3.79 \pm 4.30$; RUV $=2.02 \pm 2.30$ ), the CIs overlapped (Fig. 5G,H), suggesting that there was no clear effect of bait. There was little difference between the
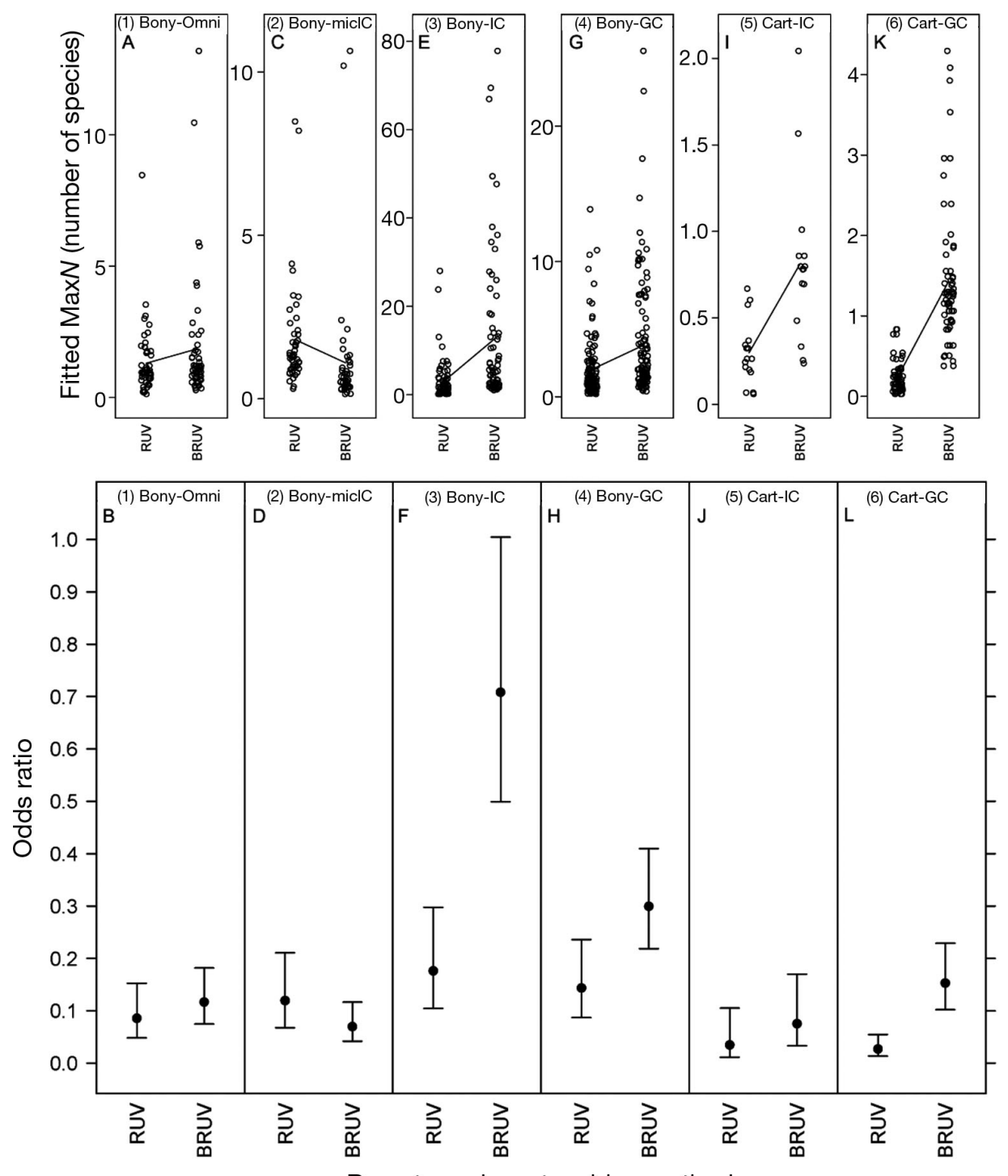

Fig. 5. Measured response in abundance by the trophic guilds to the presence of bait. The top row shows the distribution of the fitted data, with response lines between medians; the bottom row shows the difference between odds ratios ( $\pm 95 \%$ confidence intervals) for the effect of bait on the $\operatorname{Max} N$ estimates for the different trophic guilds. Bony: bony fish; cart: cartilaginous fish; omni: omnivores; micIC: microinvertebrate carnivores; IC: invertebrate carnivores; GC: generalist carnivores 
RUV and BRUV predicted MaxN for the bony omnivores (Fig. 5A,B), bony microinvertebrate carnivores (Fig. 5C,D), and the cartilaginous invertebrate carnivores (Fig. 5I,J), indicating a negligible effect of bait. In all the above cases, BRUV was predicted to yield higher count data than RUV. Only for the bony microinvertebrate carnivore group was the opposite predicted, although this pattern did not appear to be significant when visible reef was set at $40.54 \%$.

Visible reef was identified in the GLMM as having a significant effect on MaxN for both remote video methods (Table S2.3 in Supplement 2). As a result, when the odds ratios for the effect of bait on $\operatorname{Max} N$ were predicted with visible reef set to $10 \%$ cover, significant separation was evident between the CI for the RUV and BRUV for the bony invertebrate carnivores (BRUV: $0.49 \pm 0.22$; RUV: $0.06 \pm 0.34$ ), the bony generalist carnivores (BRUV: $0.21 \pm 0.21$; RUV: $0.05 \pm$ 0.33 ) and the cartilaginous generalist carnivores (BRUV: $0.11 \pm 0.24$; RUV: $0.01 \pm 0.41$ ). In contrast, when the odds ratios were predicted with visible reef set to $80 \%$, significant separation was only evident for the bony microinvertebrate carnivores, with the odds ratio of $\operatorname{Max} N$ significantly higher for RUV $(0.49 \pm 0.22)$ compared to BRUV $(0.11 \pm 0.31)$.

\section{The effect of bait on the abundance of species}

The residual deviance of the GLMMs was $>1$ for all species, suggesting that the data were overdispersed (Supplement 3 at www.int-res.com/articles/ suppl/m471p235_supp.pdf); however, analysis of the Pearson residuals showed no significant effect $(\mathrm{p}>$ 0.5 in all cases), indicating that a Poisson distribution was suitable for analysis of the variability in the data. Method (RUV or BRUV) was the only covariate retained in the best-fit model for all species (Supplement 3). The presence of bait had a positive effect on the intercept (i.e. increased the $\operatorname{Max} N$ ) for all the species except the fingerfins, where the presence of bait had a negative effect on the intercept (Supple-
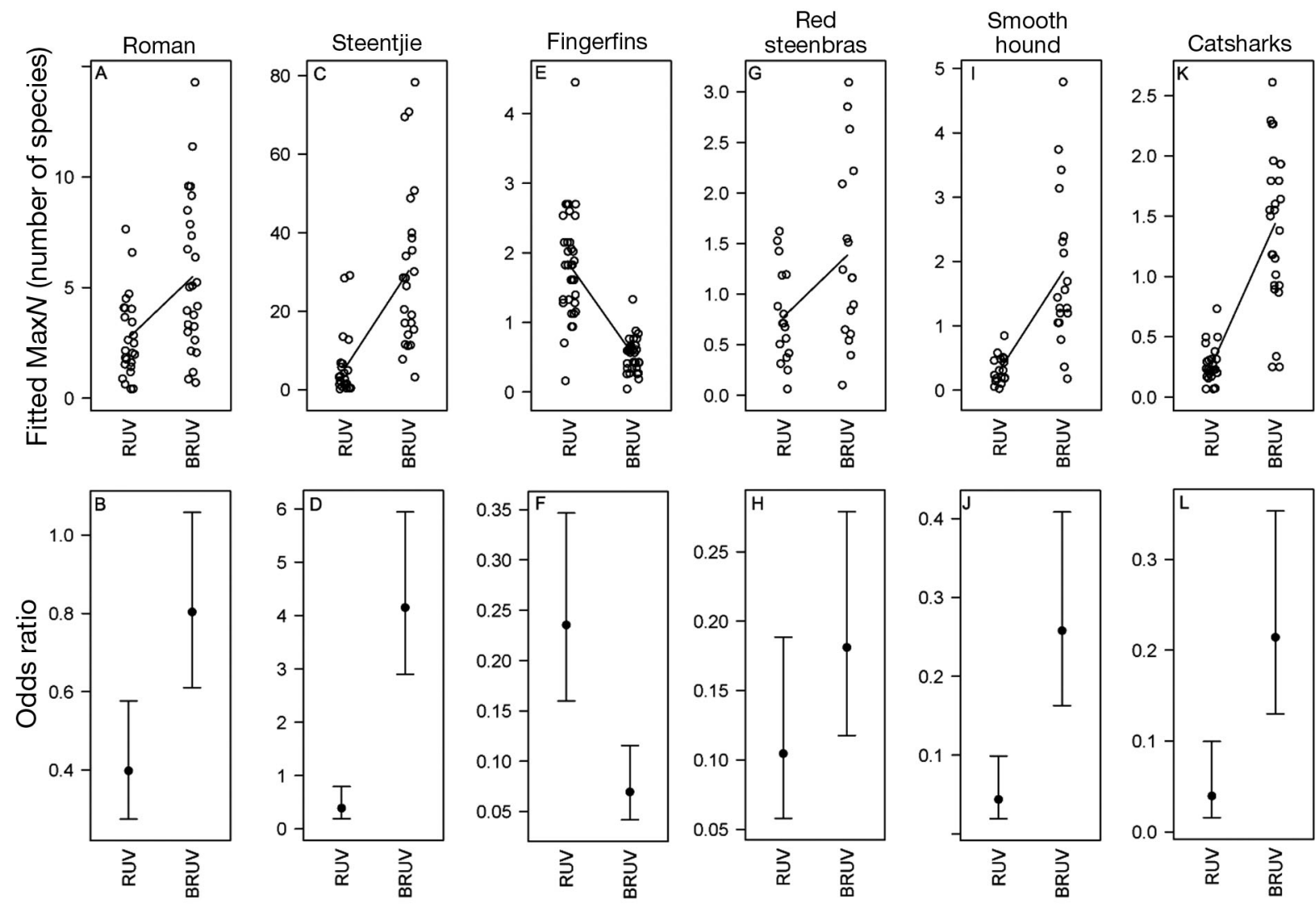

Remote underwater video method

Fig. 6. Measured response in abundance by the different species to the effect of bait. The top row shows the distribution of the fitted data, with response lines between medians; the bottom row shows the difference between odds ratios $( \pm 95 \%$ confidence intervals) for the effect of bait on the MaxN estimates for the selected species 
ment 3, Fig. 6). The scale of the bait effect was significantly different from 0 for all species except red steenbras, which were typically scarce in both the RUV and BRUV samples (Supplement 3, Fig. 6). This was reaffirmed in the comparison of the CI around the odds ratios for the effect of bait on $\operatorname{Max} N$, with only red steenbras showing no significant separation (Fig. 6G,H).

\section{Data variability and power analysis}

Roman

The abundance of roman (mean \pm SE number of individuals) from the RUV data was significantly higher on solid reef $(\operatorname{Max} N=3.00 \pm 1.83)$ compared to patch reef $(\operatorname{Max} N=1.16 \pm 1.04)$ (Table 4), and visible reef had a significant effect on $\operatorname{Max} N$ (chi squared $=6.5, \mathrm{p}<0.05$ ) with higher abundances recorded when the video had equal coverage of the reef and water column (Fig. 7A). The BRUV data showed that roman were significantly more abundant on solid reef $(\operatorname{Max} N=5.90 \pm 4.11)$ compared to patch reef $(\operatorname{Max} N=2.33 \pm 1.87)$, while the abundance was positively related to water depth (chi squared $=15.85, \mathrm{p}<0.01)$ (Table 4). Results from the power analysis indicated that to observe a doubling or halving of the roman population with a statistical power of 0.8 at a significance level of 0.05, 15 samples were required for RUV, while only 8 were required when sampling with BRUV (Table 4).

\section{Steentjie}

The abundance of steentjies in the RUV data showed a significant positive correlation with water depth (chi-squared $=20.76, \mathrm{p}<0.001$ ) and temperature (chi-squared $=48.5, \mathrm{p}<0.001$ ) (Table 4 ), while visible reef had a significant effect on $\operatorname{Max} N$ (chi-squared $=40.20, \mathrm{p}<0.001$ ), with abundance predicted to be highest when the video had equal coverage of the reef and water column (Fig. 7B). The analysis of the BRUV data indicated that higher counts of steentjies were significantly associated with solid rock $(\operatorname{Max} N=30.8 \pm 24.89)$ compared to patch reef $(\operatorname{Max} N=15.17 \pm 13.22)$. A slight, but significant, negative effect of visible reef (chi-squared $=15.85$, $\mathrm{p}<0.001$ ) (Fig 7C), together with a significant positive effect of temperature (chi-squared $=215.76, \mathrm{p}<$ 0.001), was evident in the BRUV steentjie data. There was a considerable difference in the number of samples to detect an effect size of 2, with the BRUV requiring 11 samples and the RUV requiring 78 samples.

\section{Fingerfins}

The GAM of the RUV data showed that fingerfins were significantly more abundant on high profile reef $(\operatorname{Max} N=3.67 \pm 2.71)$ compared to low profile reef $(\operatorname{Max} N=0.92 \pm 0.97)$. Fingerfin abundance increased significantly with increasing visible reef (chi-squared = 12.68, p < 0.001) (Fig. 7D), depth (chisquared $=8.89, \mathrm{p}<0.01$ ), and temperature (chi-

Table 4. Results from the likelihood ratio test runs on the generalised additive models investigating the effect of environmental variables on observed variability for the selected species, employing the unbaited (RUV) and baited (BRUV) remote underwater video methods. Continuous variables fitted with a tensor product smooth term (te) are indicated by te(variable); edf: estimated degrees of freedom; $-:$ no data ${ }^{-}<0.1,{ }^{*}<0.05,{ }^{* *}<0.01,{ }^{* * *}<0.001$

\begin{tabular}{|c|c|c|c|c|c|c|c|c|c|c|c|c|}
\hline & \multicolumn{4}{|c|}{ Roman } & \multicolumn{4}{|c|}{ Steentjie } & \multicolumn{4}{|c|}{ Fingerfins - } \\
\hline & \multicolumn{2}{|c|}{ RUV } & \multicolumn{2}{|c|}{ BRUV } & \multicolumn{2}{|r|}{ RUV } & \multicolumn{2}{|c|}{ BRUV } & \multicolumn{2}{|c|}{ RUV } & \multicolumn{2}{|c|}{ BRUV } \\
\hline & $\mathrm{df} / \mathrm{edf}$ & $\chi^{2}$ & df/edf & $\chi^{2}$ & df/edf & $\chi^{2}$ & $\mathrm{df} / \mathrm{edf}$ & $\chi^{2}$ & df/edf & $\chi^{2}$ & df/edf & $\chi^{2}$ \\
\hline Bottom & 1 & $7.31^{* *}$ & 1 & $14.19^{* * *}$ & - & - & 1 & $138^{* * *}$ & - & - & - & - \\
\hline Profile & - & - & - & - & - & - & - & - & 1 & $7.78^{* *}$ & 1 & $7.32^{* *}$ \\
\hline te(Visible reef) & 1.29 & $6.54^{*}$ & - & - & 1.89 & $40.20^{* * *}$ & 1.76 & $15.85^{* * *}$ & 0.93 & $12.68^{* * *}$ & - & - \\
\hline te(Depth) & 0.81 & 1.86 & 2.88 & $15.85^{* *}$ & 1 & $20.76^{* * *}$ & - & - & 0.90 & $8.89^{* *}$ & - & - \\
\hline te(Temperature) & - & - & - & - & 3.709 & $48.52^{* * *}$ & 2.93 & $215.76^{* * *}$ & 2.80 & $25.64^{* * *}$ & 1.64 & 4.38 \\
\hline & 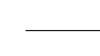 & - Red s & eenbras & $\mathrm{s}$ & 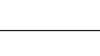 & — Smooth & -hound & - & 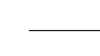 & — Cats & harks & \\
\hline Bottom & - & - & - & - & - & - & - & - & - & - & - & - \\
\hline Profile & - & - & - & - & - & - & 1 & $11.08^{* * *}$ & 1 & 1.42 & 1 & $6.22^{*}$ \\
\hline te(Visible reef) & - & - & - & - & - & - & - & - & - & - & - & - \\
\hline te(Depth) & 1.22 & $5.03^{-}$ & 0.74 & $2.71^{-}$ & 1.46 & 2.74 & - & - & - & - & - & - \\
\hline te(Temperature) & - & - & - & - & - & - & 1.22 & $6.94^{*}$ & 2.14 & 3.05 & 2.79 & $18.96^{* * *}$ \\
\hline
\end{tabular}



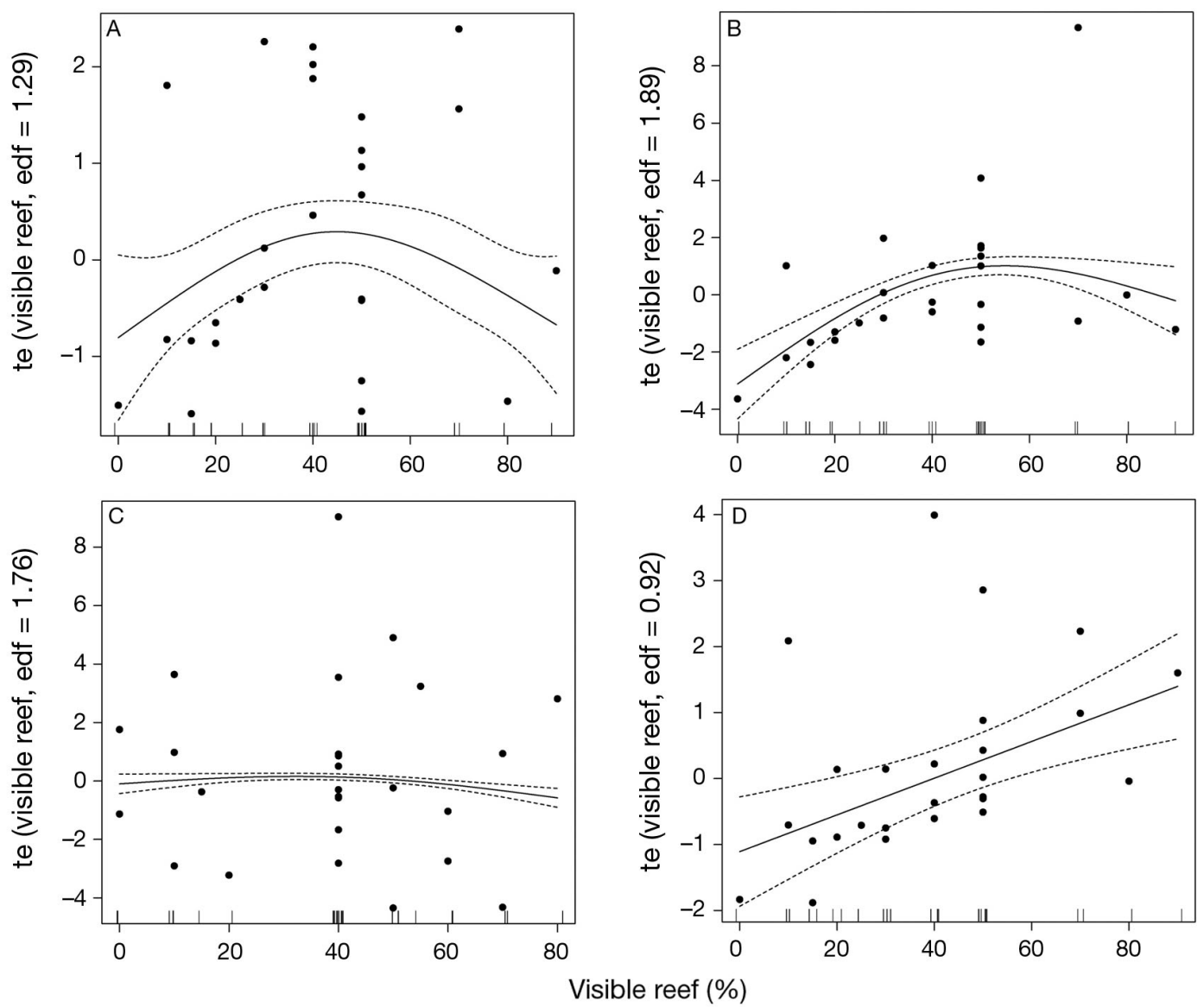

Fig. 7. Log odds ratios for the effect of visible reef (percentage cover of reef in the video frame) on Max $N$ of (A) roman, (B) steentjie and (D) fingerfins sampled with the RUV, and (C) steentjie sampled with the BRUV. The solid line represents the log odds ratio, and the dotted lines the $95 \%$ confidence intervals. te: tensor product smooth term; edf: estimated degrees of freedom

squared $=25.64, \mathrm{p}<0.001)($ Table 4$)$. As with the RUV data, the BRUV data were characterized by significantly higher predicted counts for fingerfins on high profile reef $(\operatorname{Max} N=1.07 \pm 0.76)$ compared to low profile reef $(\operatorname{Max} N=0.25 \pm 0.76)$. The results from the power analysis indicated that RUV required 14 samples to be able to detect an effect size of 2 , while BRUV required 22 samples. This appears to be the exception to the norm, and confirms the observed negative effect of bait on fingerfins.

\section{Red steenbras}

The selected models for the BRUV and RUV methods on the red steenbras Max $N$ data were very similar (Table 4), with only the smoothing term for depth included in the models. In both instances depth was found to increase the predicted counts, but not significantly (RUV: chi-squared $=5.03, p=0.058$; BRUV: chisquared $=2.71, p=0.091$ ). Due to the high deviance in the count data, together with a low predicted mean, the required sample sizes were large for both BRUV and RUV, with 27 and 41 samples required, respectively, to detect an effect size of 2 (Table 4).

\section{Smooth-hound}

The environmental variables included in the GAM of the RUV data were unable to significantly account for any of the variability in the data. Alternatively, the BRUV data indicated that smooth-hound sharks showed an opposite trend to the teleosts, with significantly higher abundances observed on low profile reef (odds ratio $=0.26, \operatorname{Max} N=2.17 \pm 1.82$ ) compared to high profile reef, while their abundance was significantly positively related to water temperature (chi-squared $=6.94, \mathrm{p}<0.05)$. The power analysis estimated that the minimum number of samples to detect an effect size of 2 for the BRUV was 21, while 65 samples were needed when sampling with RUV. 


\section{Catsharks}

As with the smooth-hound, the environmental parameters included in the GAM of the RUV data were unable to significantly account for any of the observed variability in catshark abundance, emphasising the method's inability to survey components of the shark community. With the BRUV data the abundance of catsharks was significantly higher on solid reef $(\operatorname{Max} N=1.62 \pm 1.14)$ compared to patch reef $(\operatorname{Max} N=1.0 \pm 1.24)$, while a $\operatorname{Max} N$ displayed a significant negative response to increasing water temperature (chi-squared $=18.96, \mathrm{p}<0.001$ ) (Table 4). The power analysis produced results similar to those from the smooth-hound shark analysis, with 26 samples and 68 samples required by BRUV and RUV (Table 4), respectively.

\section{DISCUSSION}

\section{The effect of bait on the optimal deployment time}

Numerous deployment times were selected in past studies that collected data with remote video. For example, Watson et al. (2005) selected deployment times of 15 min; Babcock et al. (1999), Willis \& Babcock (2000), Willis et al. (2000, 2003), Langois et al. (2011) and Malcolm et al. (2007) deployed their cameras for $30 \mathrm{~min}$, while Harvey et al. (2007), Watson et al. $(2007,2009)$ and Colton \& Swearer (2010) selected a 60 min deployment time. This study selected a 60 min deployment time, although the analysis of the accumulation of species indicated that only $29 \mathrm{~min}$ were required to detect $95 \%$ of the species observed, while 48 min were required to detect $95 \%$ of the species at their maximum abundance. This agrees with past investigations of optimal deployment time of BRUV systems that identified a minimum of $35 \mathrm{~min}$ (Stobart et al. 2007) and 36 min (Watson et al. 2007) to record the majority of the species, while longer deployments of up to $60 \mathrm{~min}$ were recommended to comprehensively survey the fish community (Watson et al. 2007). None of the past studies have calculated the optimal deployment time for RUV, but analysis in this study indicates that considerably shorter deployment times can be employed for the unbaited (35 min) compared to the baited method to detect $95 \%$ of the species at their maximum abundance. However, much of this difference can be attributed to the lower number of species sampled with RUV. The agreement between the results from this study and past work adds to the global method development for sampling temperate rocky reef fish communities by means of RUV and BRUV, and promotes the use of minimum deployment times of 35 and $50 \mathrm{~min}$, respectively.

\section{The effect of bait on the observed fish community}

Past research on Rheeders Reef recorded 30 species during UVC line transects and point counts (Bennett 2007, Bennett et al. 2009). The remote video methods sampled 53 species, of which 48 were identified down to species level; $36 \%$ greater than both UVC techniques. The BRUV method observed 46 of the 48 recorded species, while only 34 species were observed in the RUV footage, demonstrating the superiority of the baited video technique. In South Africa, sparid fish show a high degree of endemism (Branch et al. 2010), with 19 endemic species reported from the vicinity of the TNP MPA. The results from this study show that both BRUV (15 species) and RUV (12 species) sample the same endemic species as efficiently as UVC (13 species) (Bennett 2007). The sharks, skates and rays sampled by the remote video techniques accounted for most of the observed difference in species richness compared to the UVC. Bennett (2007) reported only 2 cartilaginous species with UVC, while RUV recorded 7, and BRUV recorded 13 cartilaginous species. Colton \& Swearer (2010) reported similar results, with elasmobranchs accounting for the higher taxonomic distinctness in BRUV compared to UVC samples.

Only one other study has directly compared the ability of BRUV and RUV to sample different trophic components of the demersal fish community. While Harvey et al. (2007) identified that bait had little effect on the observed abundance of herbivorous and omnivorous fish species, they identified a significant positive effect on the count data for piscivores, generalist carnivores, microinvertebrate carnivores and invertebrate carnivores sampled in temperate waters. The results from this study are generally in agreement: counts from all but one of the trophic guilds were higher when sampled with bait. Interestingly, much of the observed effect on the generalist carnivores was attributed to the dominant primary fisheries species, roman, while scarcer species of high conservation concern and important fisheries targets, such as red steenbras and dageraad Chrysoblephus cristiceps (Sink et al. 2012), showed only a slight response to the presence of bait.

The exception to the typically positive response to bait was observed in the microinvertebrate carnivore 
group, which showed a $39 \%$ drop in abundance when bait was present. This was mostly attributed to the fingerfins, which were $3 \times$ more abundant in the absence of bait. Harvey et al. (2007) found that temperate microinvertebrate carnivore species were significantly better sampled by BRUV than RUV, while there was no significant difference in the abundance estimates for the algae/invertebrate feeders or the true herbivores. These contrasting results may reflect differences in the structure and behaviour of the fish communities and oceanographic conditions. Although Harvey et al. (2007) did not report the average visibility observed during their study, they were able to identify fish up to $7 \mathrm{~m}$ away from the camera, suggesting that it was generally greater than the $4 \mathrm{~m}$ average recorded in this study. Harvey et al. (2007) found that many of the herbivorous and omnivorous species could be seen in the background of the BRUV footage, and it is likely that the better visibility aided identification. In this study, the density of fish, particularly steentjies, around the bait container often obscured the view of the background, while the poor visibility eliminated the possibility of observing and correctly identifying species that were present but not attracted to the bait. This effect was likely compounded by avoidance behaviour by the non-carnivorous species, such as the fingerfins, cape knifejaw Oplegnathus conwayi, zebra Diplodus hottentotus and janbruin Gymnocrotaphus curvidens, in response to the high level of activity of predators at the bait container.

In comparison to UVC, RUV appears to be a reliable method for obtaining unbiased abundance estimates for dominant and conspicuous reef fish species (Francour et al. 1999). Compared to past data collected in the TNP MPA by UCV (Bennett 2007) the RUV method appears to under-sample the dominant microinvertebrate carnivore species, the twotone fingerfin Chirodactylus brachydactylus and barred fingerfin Cheilodactylus pixi, which are better surveyed by UVC. Simultaneously, RUV appears better at surveying the scarcer redfingers Cheilodactylus fasciatus, cape knifejaw, and janbruin. Considering that RUV typically surveyed an area less than $10 \mathrm{~m}^{2}$, it is unrealistic to expect the method to produce similar count data to UVC (expressed over $100 \mathrm{~m}^{2}$ ). When the survey areas are standardized, UVC shows lower counts than RUV. For example, steentjie and red steenbras are $100 \times$ and $33 \times$ more abundant, respectively, and roman, cape knifejaw, and janbruin are each 10x more abundant in RUV data compared to UVC data. A combination of factors may have contributed to this disparity, including an underestimate of the survey area in RUV and a combination of avoidance and attraction to divers during UVC.

It is well documented that a number of factors contribute to inaccuracies in UVC count data (Edgar et al. 2004); however, the consistently higher abundance in RUV data suggests that other factors were at play. Water visibility during dive surveys in the TNP MPA is typically $\sim 4 \mathrm{~m}$ (A.T.F. Bernard, pers. obs.) and as a result the visibility calculations from this study $($ mean $=3.85 \mathrm{~m})$ appear realistic. Alternatively, it is possible that $\operatorname{Max} N$ is not a suitable measure of abundance for RUV data, overestimating the number of fish in the visible area, and restricting the ability to calculate density.

One of the strengths of BRUV over RUV is its ability to sample cartilaginous fishes (Cappo et al. 2004, Brooks et al. 2011). This was clearly demonstrated by the 6 -fold increase in abundance of cartilaginous generalist carnivores when bait was included as an attractant. Very few methods have a similar ability to sample shallow subtidal rocky reef shark populations. Controlled angling (CA) was employed to survey the fish communities in the TNP (Bennett 2007) and Goukamma MPAs (Götz 2005), but in both instances insufficient sharks were captured to warrant independent assessments of their populations. Most catsharks occurring on temperate rocky reefs in South Africa are endemic to the region (Branch et al. 2010), and recent reports suggest that there have been declines in the abundance of striped catsharks Poroderma africanum (Sink et al. 2012). Considering this, there is a need to monitor future changes in this species' population, and BRUV may offer an ideal, non-destructive sampling tool.

Consistently higher abundance is a convenient characteristic of data for analysis, as it is associated with proportionally smaller variation around the mean (Thompson \& Mapstone 1997), while at the same time it is less likely to be zero-inflated (Cunningham \& Lindenmayer 2005). For trends in data to be statistically significant, the variability around the mean needs to be low, i.e. to have a low noise to signal ratio (Vos et al. 2000). Consequently, methods that consistently sample species at high abundances would improve diagnostic capability in long-term monitoring. As such, the higher counts per species recorded with BRUV (compared directly to RUV and indirectly to UVC and CA) suggest that it is the preferred tool for long-term monitoring.

The reduced variability around a mean described above was clearly evident in the power analysis for the individual species, which favoured BRUV for all species except the fingerfins. Considering the spe- 
cific species analysed during this study, a BRUV survey would require 27 samples to detect a doubling or halving of the populations, while a RUV survey would require 78 samples. Bennett et al. (2009), employing the same power analysis procedure, found that to efficiently sample the roman population with UVC or CA, at least 15 and 12 samples were required to detect a doubling or halving of the population, respectively. The results from this study suggest that RUV would require the same number of samples as UVC ( $\mathrm{n}=15$ ) while BRUV was the most efficient method, requiring only 8 samples to efficiently sample the roman population.

The extensive post-sampling analysis time is a weakness of BRUV (Cappo et al. 2003, Colton \& Swearer 2010). In this study, $5.68 \pm 2.31 \mathrm{~h}($ mean $\pm \mathrm{SE}$ ) were required to extract the Max $N$ data from BRUV samples. This equates to $7.0 \mathrm{~h}$ to complete 1 station with the 50 min optimal deployment time and $30 \mathrm{~min}$ to move between stations, deploy and retrieve the camera system. On the other hand, the RUV method required considerably shorter post-sampling analysis time, with data extraction taking on average $2.39 \pm$ $1.31 \mathrm{~h}$, and a complete sampling time of $3.5 \mathrm{~h}$. Extrapolating this sampling time by the number of samples required to detect a doubling or halving of the roman population, the total sampling effort required was 56.1 and $52.1 \mathrm{~h}$ for BRUV and RUV, respectively. This suggests that RUV may in fact be a more time efficient tool to survey common and conspicuous fish species. As a core function of biological monitoring is to collect accurate and precise data, intensive postsampling time should not be considered a weakness, especially if higher diagnostic power is the end result. Furthermore, sea time is considerably more expensive, and dependent on suitable weather conditions, than laboratory time. Thus, the consistently high diagnostic power from fewer samples for multiple species achieved by BRUV overrides the cost of greater overall sampling effort.

The response to bait was non-systematic among the different trophic guilds, with a much larger effect evident on the invertebrate carnivores compared to the generalist carnivores. Similarly, the analysis at species level revealed a 2 -fold to 5 -fold increase in abundance when bait was present. However, the response was not always positive, with a 3 -fold decrease seen in fingerfin abundance when bait was used. This highlights a non-systematic effect of bait on the observed fish community, with certain groups of species responding more rapidly and from further away than others. From a sampling perspective, the variable speed of response can be accounted for by selecting the optimal deploy- ment time; however, the distance that a fish is willing to move in search of food cannot be controlled and complicates the calculation of absolute density, as the survey area will not be consistent within a set plume area for different species. If BRUV data are to be standardized, the area of attraction should be considered at the species level; the change in abundance between BRUV and RUV samples (i.e. the effect size measured in this study) may provide sufficient information to infer the area of attraction. However, for RUV data, further effort needs to be invested to determine an ecologically realistic measure of abundance from which density can be estimated.

Both remote video methods are prone to biases that will reduce their sensitivity to long-term changes in fish communities. With BRUV this is because the Max $N$ is a conservative estimate of abundance (Willis \& Babcock 2000, Cappo et al. 2004), while for RUV it is because natural variability is not dampened by the attraction of bait. An indirect approach to measure the sensitivity of a method to changes in species abundance is to use known patterns of spatial variation of species abundance, either related to habitat type (structurally complex versus structurally simple reef) or management status (protected versus exploited). In this regard, BRUV appeared considerably more sensitive than RUV in detecting spatial variability associated with habitat type, which is known to influence the abundance of different fish species in the Agulhas bioregion of South Africa (Götz et al. 2008). Watson et al. (2005) and Harvey et al. (2007) found similar results when comparing the efficiency of baited and unbaited video techniques at detecting differences among various subtidal habitats.

Cappo et al. (2004) noted that variability in water visibility had a dramatic effect on BRUV performance. This effect was not directly assessed in the present study; however, it is noted that low visibility will reduce the sensitivity of data collected by both remote video methods. For BRUV, low visibility will increase the chance of saturating the field of view, while for RUV, the visible area will shrink, thereby reducing abundance estimates and increasing the chance of zero counts. In structurally complex habitats, the percentage cover of reef in the frame of view of the remote camera system will vary between samples. This study indicates that the amount of reef in the video footage affects the community composition and abundance of specific species seen when sampling with RUV, and to a lesser degree with BRUV. This methodological bias can introduce undesirable uncertainty into the data and should be accounted for during data analysis, particularly when using RUV. 


\section{CONCLUSIONS}

Baited remote underwater video appears to be a promising method to survey subtidal reef fish communities along the South African coastline. It offers an effective, fishery independent tool to monitor species that were previously ignored. Although stereoBRUV was not employed in this study, the additional benefits of this approach are well documented (Watson et al. 2005, 2010, Langlois et al. 2010, Harvey et al. 2012). Stereo-BRUV provides a standard method to survey fish throughout their depth distribution and provides accurate length estimates to investigate stock status. The RUV approach is very appealing as it is the closest one can get to a non-invasive method, but the required number of samples to obtain data with a high statistical power is unfeasible for longterm monitoring programmes. Consequently, the benefits gained by sampling the fish community under natural conditions (i.e. with RUV) do not outweigh those obtained by altering the community through the presence of bait, while the efficiency of BRUV at surveying a broader range of species makes it the preferred remote video method. However, in combination, the 2 methods offer a highly effective monitoring suite that will outcompete all other subtidal monitoring techniques, including UVC and CA.

Acknowledgements. Funding for this research was provided by the British Ecological Society, the National Research Foundation of South Africa, the Mellon Foundation, and the Elwandle Node of the South African Environmental Observation Network. We thank SANParks and CapeNature for their assistance in the field, and Professor A. Booth for assistance with the statistical analysis. We also thank the 3 anonymous reviewers for their constructive comments on this manuscript.

\section{LITERATURE CITED}

Babcock RC, Kelly S, Shears NT, Walker JW, Willis TJ (1999) Changes in community structure in temperate marine reserves. Mar Ecol Prog Ser 189:125-134

Bailey DM, Priede IG (2002) Predicting fish behaviour in response to abyssal food falls. Mar Biol 141:831-840

Bates D, Sarkar D (2011) lme4: linear mixed-effects models using S4 classes. R package, version 0.999375-41. www. cran.r-project.org/web/packages/lme4/index.html

Bennett RH (2007) Optimisation of a sampling protocol for long-term monitoring of temperate reef fishes. MSc dissertation, Rhodes University, Grahamstown

> Bennett RH, Götz A, Sauer WHH, Cowley PD, Palmer RM (2009) Optimisation of underwater visual census and controlled angling methods for monitoring subtidal temperate reef fish communities. Afr J Mar Sci 31:277-287

Birt MJ, Harvey ES, Langlois TJ (2012) Within and between day variability in temperate reef fish assemblages: learned response to baited video. J Exp Mar Biol Ecol 416-417:92-100

Bolker BM, Brooks ME, Clark CJ, Geange SW, Poulsen JR, Stevens MHH, White JSS (2009) Generalized linear mixed models: a practical guide for ecology and evolution. Trends Ecol Evol 24:127-135

Branch GM, Griffiths CL, Branch ML, Beckley LE (2010) Two oceans: a guide to the marine life of Southern Africa. Struik Nature, Cape Town

Brooks EJ, Sloman KA, Sims DW, Danychuk AJ (2011) Validating the use of baited remote underwater video surveys for assessing the diversity, distribution and abundance of sharks in the Bahamas. Endang Species Res 13:231-243

Cappo M, Harvey E, Malcolm H, Speare P (2003) Potential of video techniques to monitor diversity, abundance and size of fish in studies of marine protected areas. In: Beumer JP, Grant A, Smith DC (eds) Aquatic protected areas: What works best and how do we know? Proc World Congr Aquat Protected Areas, August 2002, Cairns. Australian Society of Fish Biology, Cairns, p 455-464

Cappo M, Speare P, De'ath G (2004) Comparison of baited remote underwater video stations (BRUVS) and prawn (shrimp) trawls for assessments of fish biodiversity in inter-reefal areas of the Great Barrier Reef marine park. J Exp Mar Biol Ecol 302:123-152

> Cappo M, De'ath G, Speare P (2007a) Inter-reef vertebrate communities of the Great Barrier Reef Marine Park determined by baited remote underwater video stations. Mar Ecol Prog Ser 350:209-221

Cappo M, Harvey ES, Shortis M (2007b) Counting and measuring fish with baited video techniques-an overview. In: Lyle JM, Furlani DM, Buxton CD (eds) Cutting-edge technologies in fish and fisheries science. Australian Society for Fish Biology, 2006 Workshop Proceedings, Hobart, August 2006, Australian Society of Fish Biology, Hobart, p 101-114

Cheung WWL, Meeuwig JJ, Feng M, Harvey E and others (2012) Climate-change induced tropicalisation of marine communities in Western Australia. Mar Freshw Res 63: 415-427

> Colton MA, Swearer SE (2010) A comparison of two survey methods: differences between underwater visual census and baited remote underwater video. Mar Ecol Prog Ser 400:19-36

> Cunningham RB, Lindenmayer DB (2005) Modelling count data of rare species: some statistical issues. Ecology 86: 1135-1142

> Edgar GJ, Barrett NS, Morton AJ (2004) Biases associated with the use of underwater visual census techniques to quantify the density and size structure of fish populations. J Exp Mar Biol Ecol 308:269-290

Ellis DM, DeMartini EE (1995) Evaluation of a video camera technique for indexing pink snapper, Pristipomoides filamentosus, and other Hawaiian insular shelf fishes. Fish Bull 93:67-77

Francour P, Liret C, Harvey E (1999) Comparisons of fish abundance estimates made by remote underwater video and visual census. Naturalistica Sicil. XXIII(Suppl): $155-168$

Goetze JS, Langlois TJ, Egli DP, Harvey ES (2011) Evidence of artisanal fishing impacts and depth refuge in assemblages of Fijian reef fish. Coral Reefs 30:507-517

Götz A (2005) Assessment of the effect of Goukamma mar- 
ine protected area on community structure and fishery dynamics. PhD dissertation, Rhodes University, Grahamstown

Götz A, Kerwath SE, Attwood CG, Sauer WHH (2008) Effects of fishing on population structure and life history of roman Chrysoblephus laticeps (Sparidea). Mar Ecol Prog Ser 362:245-259

Harvey ES, Shortis M (1996) A system for stereo-video measurement of sub-tidal organisms. Mar Tech Soc J 29: $10-22$

Harvey ES, Shortis MR, Stadler M, Cappo M (2002) A comparison of the accuracy of measurements from single and stereo-video systems. Mar Tech Soc J 36:38-49

Harvey ES, Fletcher D, Shortis MR, Kendirck GA (2004) A comparison of underwater visual distance estimates made by scuba divers and a stereo-video system: implications for underwater visual census of reef fish abundance. Mar Fish Res 55:573-580

Harvey ES, Cappo M, Butler JJ, Hall N, Kendrick GA (2007) Bait attraction affects the performance of remote underwater video stations in assessment of demersal fish community structure. Mar Ecol Prog Ser 350:245-254

> Harvey ES, Newman J, McLean D, Cappo M, Meeuwig JJ, Skepper CL (2012) Comparison of the relative efficiencies of stereo-BRUVs and traps for sampling tropical continental shelf demersal fishes. Fish Res 125-126:108-120

Hedley J (2003) Vidana 1.0: video analysis for cover estimation. www.marinespatialecologylab.org/recources/vidana/

- Langlois TJ, Harvey ES, Fitzpatrick B, Meeuwig JJ, Shedrawi G, Watson DL (2010) Cost-efficient sampling of fish assemblages: comparison of baited video stations and diver video transects. Aquat Biol 9:155-168

> Langlois TJ, Radford BT, Van Niel KP, Meeuwig JJ and others (2011) Consistent abundance distributions of marine fishes in an old, climatically buffered, infertile seascape. Glob Ecol Biogeogr 21:886-897

> Langlois TJ, Harvey ES, Meeuwig JJ (2012) Strong direct and inconsistent indirect effects of fishing found using stereo-video: testing indicators from fisheries closures. Ecol Indic 23:524-534

> Lindstrom MJ, Bates DM (1990) Nonlinear mixed effects models for repeated measures data. Biometrics 46: 673-687

Logan M (2010) Biostatistical design and analysis using R: a practical guide. Wiley-Blackwell, Chichester

> Malcolm HA, Gladstone W, Lindfield S, Wraith J, Lynch TP (2007) Spatial and temporal variation in reef fish assemblages of marine parks in New South Wales, Australiabaited video observations. Mar Ecol Prog Ser 350: 277-290

Mann BQ (2000) Southern African marine linefish status reports. Spec Publ No. 7, Oceanographic Research Institute, Durban

Merritt D, Donovan MK, Kelley C, Waterhouse L, Parke M, Wong K, Drazen JC (2011) BotCam: a baited camera system for nonextractive monitoring of bottomfish species. Fish Bull 109:56-67

> McLean DL, Harvey ES, Meeuwig JJ (2011) Declines in the abundance of coral trout (Plectropomus leopardus) in areas closed to fishing at the Houtman Abrolhos Islands, Western Australia. J Exp Mar Biol Ecol 406:71-78

Moore CH, Van Niel K, Harvey ES (2011) The effect of landscape composition and configuration on the spatial distribution of temperate demersal fish. Ecography 34 : 425-435
Murray SN, Ambrose RF, Dethier MN (2001) Methods for performing monitoring, impact, and ecological studies on rocky shores. MMS OCS Study 2001-070. Coastal Research Center, Marine Science Institute, University of California, Santa Barbara, CA

Pelletier D, Leleu K, Mou-Tham G, Guillemot N, Chabanet P (2011) Comparison of visual census and high definition video transects for monitoring coral reef fish assemblages. Fish Res 107:84-93

> Pelletier D, Leleu K, Mallet D, Mou-Tham G, Hervé G, Boureau M, Guilpart N (2012) Remote high-definition rotating video enables fast spatial survey of marine underwater macrofauna and habitats. PLoS ONE 7: e30536

Pinheiro J, Bates D, DebRoy S, Sarkar D, R Core team (2011) nlme: linear and nonlinear mixed effects models. R package version 3.1-202. http://cran.r-project.org/web/ packages/nlme/nlme.pdf

Priede IG, Merrett RN (1996) Estimation of abundance of abyssal demersal fishes: a comparison of data from trawls and baited cameras. J Fish Biol 49(Suppl. A):207-216

> Priede IG, Bagley PM, Smith A, Creasey S, Merrett RN (1994) Scavenging deep demersal fishes of the Porcupine Seabight, north-east Atlantic: observations by baited camera, trap and trawl. J Mar Biol Assoc UK 74:481-498

R Development Core Team (2011). R: a language and environment for statistical computing. R Foundation for Statistical Computing, Vienna. www.R-project.org/

Sarkar D (2008) Lattice: multivariate data visualization with R. Springer, New York, NY

Sink K, Holness S, Harris L, Majiedt P and others (2012) National biodiversity assessment 2011: Technical report. Volume 4: Marine and coastal component. South African National Biodiversity Institute, Pretoria

Stobart B, Garcia-Charton JA, Espejo C, Rochel E and others (2007) A baited underwater video technique to assess shallow-water Mediterranean fish assemblages: methodological evaluation. J Exp Mar Biol Ecol 345:158-174

Thompson AA, Mapstone BD (1997) Observer effects and training in underwater visual surveys of reef fishes. Mar Ecol Prog Ser 154:53-63

> Venables WN, Dichmont CM (2004) GLMs, GAMs and GLMMs: an overview of theory for applications in fisheries research. Fish Res 70:319-337

> Vos P, Meelis E, Ter Keurs WJ (2000) A framework for the design of ecological monitoring programmes as a tool for environmental and nature management. Environ Monit Assess 61:317-344

Watson DL, Harvey ES, Anderson MJ, Kendrick GA (2005) A comparison of temperate reef fish assemblages recorded by three underwater stereo-video techniques. Mar Biol 148:415-425

> Watson DL, Harvey ES, Kendrick GA, Nardi K, Anderson MJ (2007) Protection from fishing alters the species composition of fish assemblages in a temperate-tropical transition zone. Mar Biol 152:1197-1206

- Watson DL, Anderson MJ, Kendrick GA, Nardi K, Harvey ES (2009) Effects of protection from fishing on the lengths of targeted and non-targeted fish species at the Houtman Abrolhos Islands, Western Australia. Mar Ecol Prog Ser 384:241-249

Watson DL, Harvey ES, Fitzpatrick BM, Langlois TJ, Shedrawi G (2010) Assessing reef fish assemblage structure: how do different stereo-video techniques compare? Mar Biol 157:1237-1250 
Weyl OLF, Booth AJ (1999) On the life history of a cyprinid fish, Labeo cylindricus. Environ Biol Fishes 55:215-225

Willis TJ, Babcock RC (2000) A baited underwater video system for the determination of relative density of carnivorous reef fish. Mar Freshw Res 51:755-763

Willis TJ, Millar RB, Babcock RC (2000) Detection of spatial variability in relative density of fishes: comparison of visual census, angling, and baited underwater video. Mar Ecol Prog Ser 198:249-260

> Willis TJ, Millar RB, Babcock RC (2003) Protection of exploited fish in temperate regions: high density and biomass of snapper Pargus auratus (Sparidae) in northern

Editorial responsibility: Konstantinos Stergiou, Thessaloniki, Greece
New Zealand marine reserves. J Appl Ecol 40:214-227

Wood S (2006) Generalized additive models: an introduction with R. Chapman \& Hall, London

Wood SN (2011) Fast stable restricted maximum likelihood and marginal likelihood estimation of semiparametric generalized linear models. JR Stat Soc 73:3-36

Zuur AF, Ieno EN, Walker N, Saveliev AA, Smith GM (2009) Mixed effects models and extensions in ecology with $\mathrm{R}$. Springer, New York, NY

Zuur AF, Ieno EN, Elphic CS (2010) A protocol for data exploration to avoid common statistical problems. Method Ecol Evol 1:3-14

Submitted: June 7, 2012; Accepted: September 6, 2012

Proofs received from author(s): December 3, 2012 